\title{
HID-1 is a peripheral membrane protein primarily associated with the medial- and trans- Golgi apparatus
}

\author{
Lifen Wang ${ }^{1,2^{*}}$, Yi Zhan ${ }^{3^{*}}$, Eli Song ${ }^{1 *}$, Yong $\mathrm{Yu}^{1,2}$, Yaming $\mathrm{Jiu}^{3}$, Wen Du${ }^{1}$, Jingze Lu ${ }^{1}$, Pingsheng Liu ${ }^{1}$, \\ Pingyong $\mathrm{Xu}^{1} \stackrel{\mathrm{m}}{ }$, Tao $\mathrm{Xu}^{1,3 凶}$ \\ ${ }^{1}$ National Laboratory of Biomacromolecules, Institute of Biophysics, Chinese Academy of Sciences, Beijing 100101, China \\ ${ }^{2}$ Graduate School of the Chinese Academy of Sciences, Beijing 100864, China \\ ${ }^{3}$ College of Life Science and Technology, Huazhong University of Science and Technology, Wuhan 430074, China \\ $\triangle$ Correspondence: xutao@ibp.ac.cn (T. Xu), pyxu@moon.ibp.ac.cn (P. Xu) \\ Received January 11, 2011 Accepted January 18, 2011
}

\begin{abstract}
Caenorhabditis elegans hid-1 gene was first identified in a screen for mutants with a high-temperature-induced dauer formation (Hid) phenotype. Despite the fact that the hid-1 gene encodes a novel protein (HID-1) which is highly conserved from Caenorhabditis elegans to mammals, the domain structure, subcellular localization, and exact function of HID-1 remain unknown. Previous studies and various bioinformatic softwares predicted that HID-1 contained many transmembrane domains but no known functional domain. In this study, we revealed that mammalian HID-1 localized to the medial- and transGolgi apparatus as well as the cytosol, and the localization was sensitive to brefeldin A treatment. Next, we demonstrated that HID-1 was a peripheral membrane protein and dynamically shuttled between the Golgi apparatus and the cytosol. Finally, we verified that a conserved $\mathrm{N}$-terminal myristoylation site was required for HID-1 binding to the Golgi apparatus. We propose that HID-1 is probably involved in the intracellular trafficking within the Golgi region.
\end{abstract}

KEYWORDS HID-1, Golgi, peripheral membrane protein, fluorescent recovery after photobleaching, N-myristoylation

\section{INTRODUCTION}

When exposed to harsh environmental conditions, the nematode Caenorhabditis elegans (C. elegans) forms arrested third stage larvae called dauer (Cassada and Russell, 1975; Riddle, 1997; Fielenbach and Antebi, 2008). Entry into the dauer stage depends on the integration of three external environmental parameters: ambient temperature, food availability, and population density (Riddle, 1997; Fielenbach and Antebi, 2008). Internally, dauer formation is regulated by at least three metabolic signaling pathways (Riddle, 1997; Ailion and Thomas, 2003; Fielenbach and Antebi, 2008). The first is cyclic GMP signaling pathway in sensory neurons that responds to pheromone (Birnby et al., 2000). The second is transforming growth factor-beta (TGF- $\beta$ ) signaling pathway, in which release of a TGF- $\beta$-like ligand from sensory neurons leads to activation of receptors and the downstream pathways in target cells (Fielenbach and Antebi, 2008). The third is insulin signaling pathway which plays critical roles in different tissues (Apfeld and Kenyon, 1998).

The C. elegans hid-1 gene was first identified, by Ailion and Thomas, from a screen for mutants with high-temperatureinduced dauer formation (Hid) phenotype (Ailion and Thomas, 2003). The hid-1 gene encodes a highly conserved protein (HID-1) with a single homolog in Drosophila melanogaster (NM_136916), mouse (NM_175454) and Homo sapiens (NM_030630). Previous studies (Ailion and Thomas, 2003) and several bioinformatic softwares predicted that HID-1 contained many transmembrane domains but no known functional domain. Interestingly, the Hid phenotype of hid-1 mutants is strongly suppressed by mutations in daf-16 (Ailion and Thomas, 2003), a transcription factor downstream of insulin signaling, suggesting a possible action of HID-1 in the

\footnotetext{
*These authors contributed equally to this work.
} 
insulin branch of dauer pathway (Inoue and Thomas, 2000a, b). The exact cellular function of HID-1 is unclear but was hypothesized to be involved in vesicular exocytosis.

To explore the exact molecular mechanism of HID-1, we carried out the current study that presents the first picture of the expression pattern, subcellular localization and several molecular properties of mammalian HID-1. Our findings show that HID-1 was highly expressed in secretory cell lines and Golgi-like localization in INS-1 cells. Next, HID-1 localized to the medial- and trans-Golgi apparatus as well as the cytosol, and the localization was sensitive to brefeldin A (BFA). Furthermore, we provided strong evidences that Golgilocalized HID-1 was a peripheral membrane protein and dynamically shuttled between the Golgi apparatus and the cytosol, in contrast to a putative transmembrane protein. Finally, we demonstrated that a conserved $\mathrm{N}$-terminal myristoylation site was required for HID-1 binding to the Golgi apparatus.

\section{RESULTS}

\section{HID-1 expresses in secretory cell lines}

First, we tested the expression pattern of HID-1 in several cell lines, including 293ET, HeLa, CHO, PC12, INS-1, and 3T3L1, using the hHID-1 antiserum (Yu et al., 2011). As shown in Fig. 1A, endogenous HID-1 was only detected in PC12 and INS-1 cells. The results suggest that HID-1 is highly expressed in secretory cell lines, in accordance with neurosecretory functions predicted in $C$. elegans (Ailion and Thomas, 2003). In addition, to determine the subcellular localization of HID-1, we first generated a C-terminal enhanced green fluorescent protein (EGFP)-tagged recombinant protein (hHID-1-EGFP). We found this construct had the same localization with hHID-1 antiserum in INS-1 cells by immunofluorescence (data not shown), and verified that Cterminal EGFP-tagged HID-1 protein could rescue the Hid phenotype in hid-1 mutant in C. elegans (Yu et al., 2011), suggesting the fusion protein is functional. hHID-1-EGFP in INS-1 cells transfected showed different expression levels: cytosol and Golgi-like patterns in higher expression levels whereas clear Golgi-like patterns in lower expression levels in certain condition (Fig. 1B), most of which exhibited a perinuclear structure reminiscent of the Golgi complex, as well as a weak dispersed cytosolic distribution.

\section{HID-1 primarily localizes to the medial- and trans-Golgi apparatus in INS-1 cells}

We further characterized the precise localization using different Golgi markers that label the cis-Golgi (GM130) (Nakamura et al., 1995), the medial-Golgi/trans-Golgi network (Golgi-EGFP) (Gleeson et al., 1994; Yamaguchi and Fukuda, 1995) and the trans-Golgi network (TGN38-EGFP) (Luzio
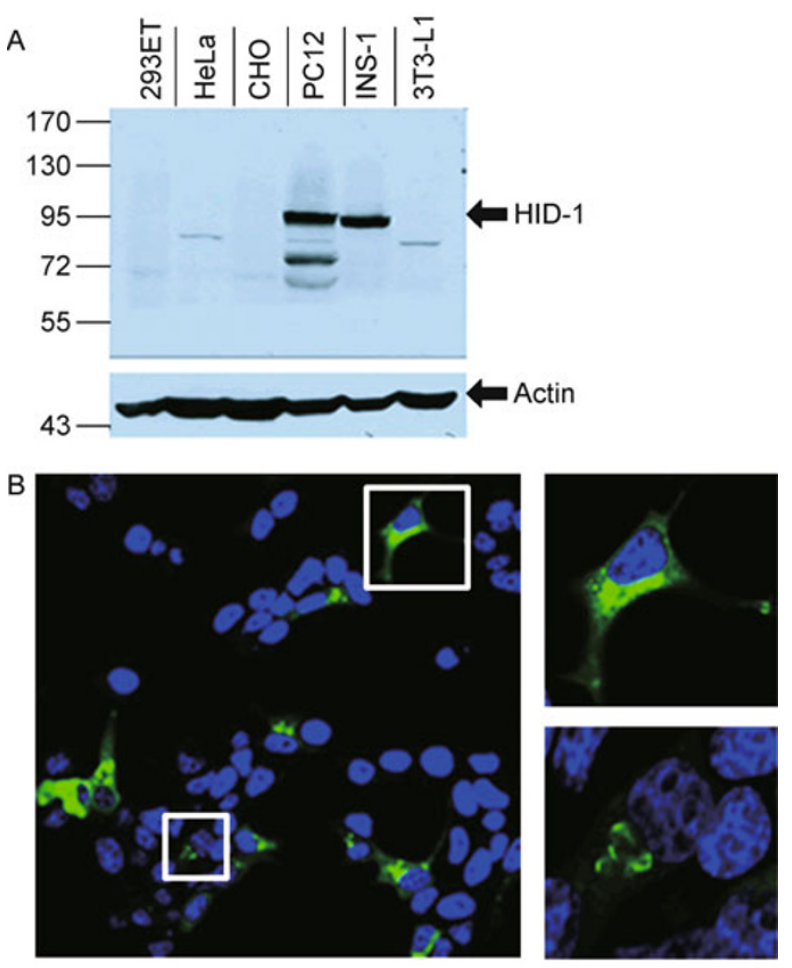

Figure 1. Expression of HID-1 in different cell lines and localization of HID-1 in INS-1 cell line. (A) The expression of HID-1 in different cell lines. Lysates of 293ET, HeLa, CHO, PC12, INS-1 and 3T3-L1 cells were immunoblotted with the hHID-1 antiserum and an anti-actin antibody. Actin was detected by an anti-actin antibody as a loading control. The positions of HID-1 and actin bands were indicated by arrows. (B) After hHID-1-EGFP was transfected in INS-1 cells for $48 \mathrm{~h}$, the cells were imaged for a smaller view on the left side. Different expression levels of the transfectant were enlarged on the right for a better view. Nuclei were labeled with Hoechst 33342 (blue).

et al., 1990; Humphrey et al., 1993). As shown in the upper panels of the Fig. 2A and B, hHID-1 co-localized nicely with Golgi-EGFP, mostly with TGN38-EGFP, and much less with GM130, suggesting that hHID-1 was primarily localized to the medial- and trans-Golgi apparatus.

Furthermore, we found that the Golgi-localization of HID-1 was sensitive to BFA, a Golgi-disturbing agent (LippincottSchwartz et al., 1991). As shown in lower panels of the Fig. $2 \mathrm{~A}$ and 2B, after $10 \mu \mathrm{M}$ BFA treatment, exogenous hHID1-EGFP mostly exhibited a dispersed distribution with some puncta structures. Moreover, part of the hHID-1-EGFP puncta structures co-localize with Golgi-EGFP but not with GM130. Similarly, the Golgi-localization of endogenous rHID-1 was also abolished after BFA treatment and partial co-localization was observed with the TGN marker, TGN46 (Fig. 2C), which is the human homology of rat TGN38 (Ponnambalam et al., 1996). 
A
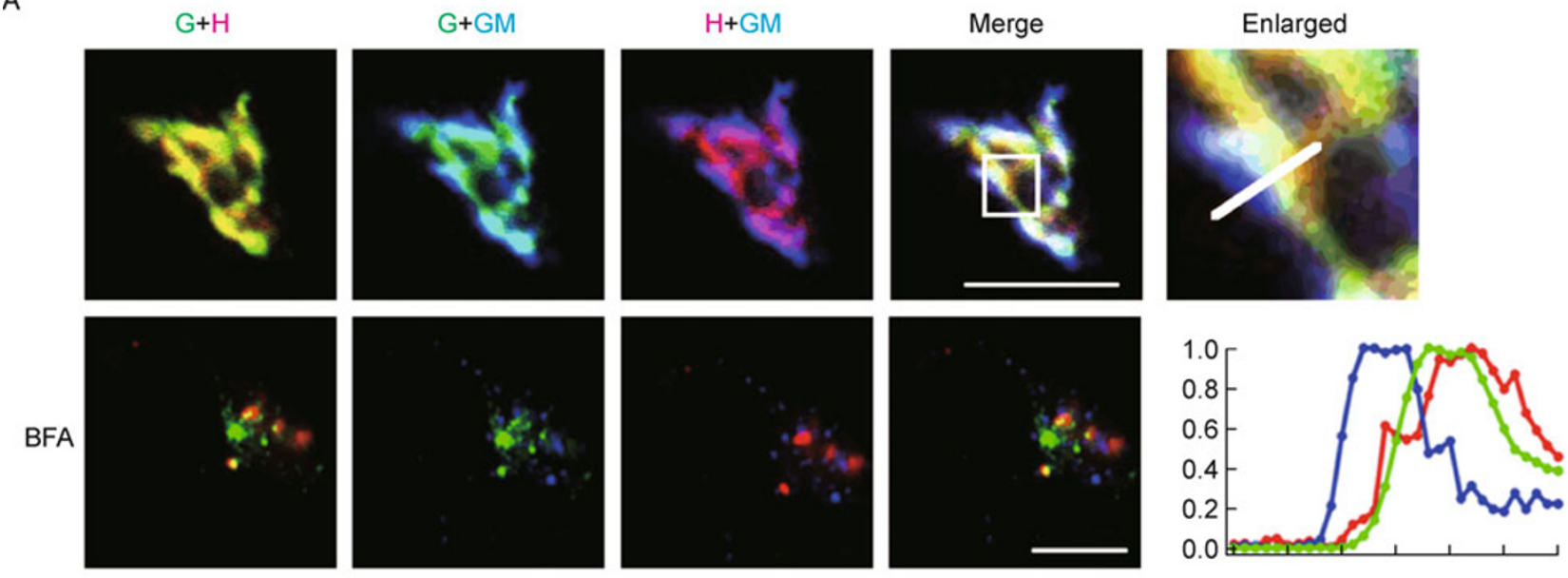

B

$\mathrm{T}+\mathrm{H}$

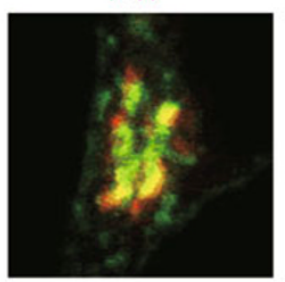

BFA

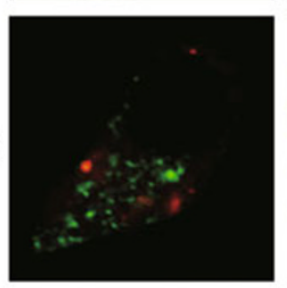

$T+G M$
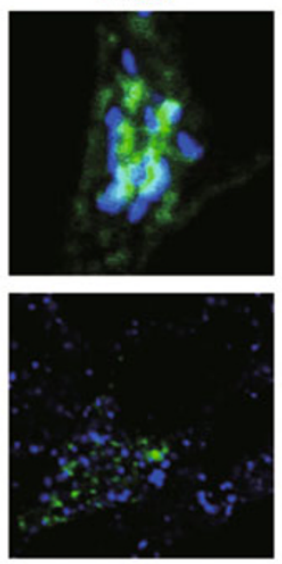

$\mathrm{H}+\mathrm{GM}$
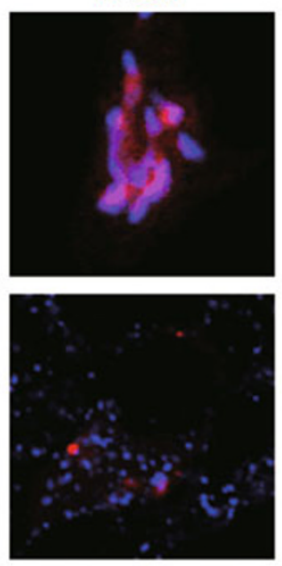

Merge
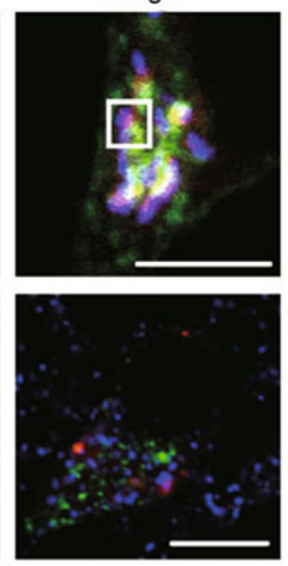

Enlarged
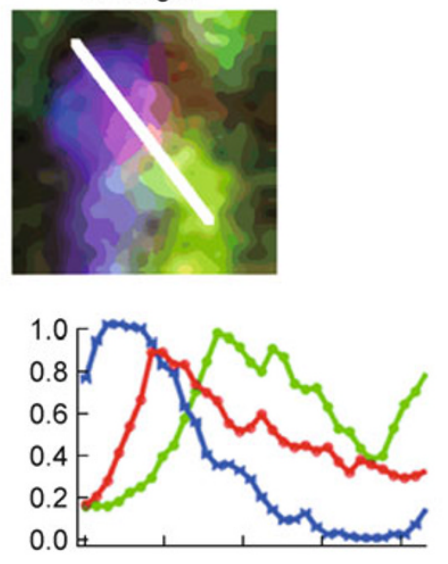

C
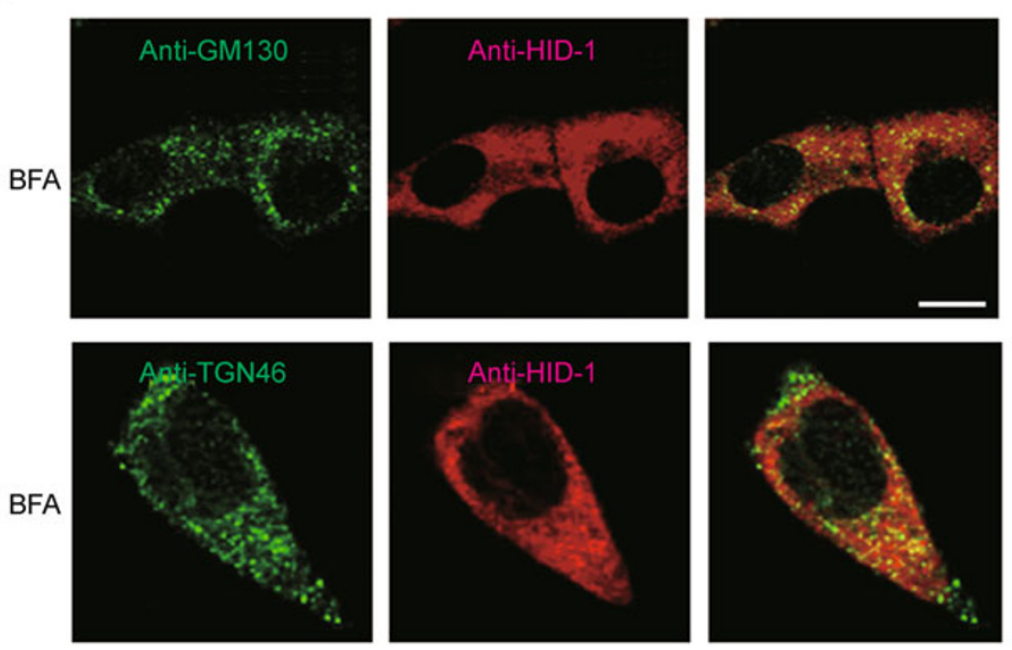

Figure 2. hHID-1 distributes primarily to the medial- and trans-Golgi apparatus. (A and $B$ ) INS-1 cells were co-transfected with hHID-1mKO and Golgi-EGFP (A) or hHID-1-mKO and TGN38-EGFP (B), and then either untreated (upper panel) or treated with $10 \mu \mathrm{M}$ BFA (lower panel). Boxed images were enlarged for a better view. The fluorescence intensity linescan profiles were generated along the white lines indicated in the enlarged images. G: Golgi-EGFP (medial-and trans-Golgi marker), H: hHID-1-mKO, GM: GM130 (cis-Golgi marker, endogenous, Cy5 used as the secondary antibody), T: TGN38-EGFP (trans-Golgi marker). Scale bar $=10 \mu \mathrm{m}$. (C) INS-1 cells were treated with BFA for $30 \mathrm{~min}$ and then immunofluorescent labled with an anti-GM130 antibody, an anti-TGN46 antibody, and the hHID-1 antiserum respectively. Scale bar $=10 \mu \mathrm{m}$. 


\section{A portion of HID-1 distributes to the cytosol}

Besides the predominant signals in the Golgi network, visible fluorescent signals were observed in the cytosol region using exogenous hHID-1-EGFP expression and immunofluorescence analysis of endogenous rHID-1 in INS-1 cells (Yu et al., 2011). To validate the cytosolic distribution of HID1 , we developed a novel method to determine the cytosolic proteins in living cells based on rapamycin-mediated heterodimerization (Choi et al., 1996) of FKBP (FK506 binding protein) (Standaert et al., 1990) and FRB (mTOR) (Brown et al., 1994). We first tagged FKBP to the C-terminus of hHID-1EGFP, and then transfected it together with lyn11 (plasma membrane marker)-FRB (Suh et al., 2006) and GolgiTDimer2 into INS-1 cells. As shown in Fig. 4, hHID-1-EGFPFKBP primarily co-localized with Golgi-TDimer2 in control cells without rapamycin. After addition of rapamycin, weak fluorescent signals of hHID-1-EGFP-FKBP in the cytosol disappeared and distinct signals were observed at the plasma membrane, whereas no apparent change was observed for the transmembrane Golgi marker, Golgi-TDimer2. The results assured the partial localization of HID-1 to the cytosol. The method we developed here provides a robust alternative to determine whether a protein actually expresses in the cytosol, as opposed to the classic biochemical ultra-centrifugation assays (Nakamura et al., 1995; Liang and Li, 2000; Luo et al., 2008).

\section{HID-1 is a peripheral membrane protein}

The hydropathy plot of HID-1 protein was analyzed by various softwares to predict its transmembrane domain(s). Several softwares, including TMpred, HMMTOP2.0, DAS, and Toppred2, predicted multiple transmembrane domains in HID-1. The results suggest that HID-1 contains two highly hydrophobic domains from amino acids 416 to 437 and 509 to 532 ; however, both of them failed to reach the threshold set by TMHMM2.0.

To address whether HID-1 is a transmembrane protein, we employed both an in vitro biochemical membrane fraction analysis (Nakamura et al., 1995; Liang and Li, 2000; Luo et al., 2008) and an in vivo permeabilization assay in living cells (Lorenz et al., 2006; Dimitrov et al., 2009). In the biochemical assay, INS-1 cells were ultracentrifuged to obtain the cytosolic fraction (the supernatant, $\mathrm{S}$ ) and the membrane fraction (the pellet, $\mathrm{P}$ ). Solutions with high salt, high $\mathrm{pH}$, and $1 \%$ Triton X-100 were used to extract proteins from the membrane fraction, respectively. The different fraction samples were immunoblotted with anti-hHID-1 antiserum and anti-Syntaxin 1A antibody. As shown in Fig. 5, rHID-1 was primarily detected in the membrane fraction and also observed in the cytosol, which was consistent with the cytosolic expression determined by the rapamycin-based method we developed (Fig. 4). Notably, treatment with $0.1 \mathrm{M}$
$\mathrm{Na}_{2} \mathrm{CO}_{3}(\mathrm{pH}$ 11.5) caused rHID-1 to be released from the membrane fraction into the soluble fraction; however, $1 \mathrm{M}$ $\mathrm{NaCl}$ and $1 \%$ Triton $\mathrm{X}-100$ solution did not cause its release. As a control, the integral membrane protein marker Syntaxin 1A (Koh et al., 1993; Lewis et al., 2001; Trus et al., 2001) failed to dissociate into the supernatant in high salt or high $\mathrm{pH}$ solutions, but dissolved in $1 \%$ Triton X-100 solution. Another control, an integral membrane protein transferring receptor (Zerial et al., 1986; Campellone et al., 2008), which is cycled between the plasma membrane and early endosome (Killisch et al., 1992), was also used, and the same distribution with Syntaxin $1 \mathrm{~A}$ was observed (data not shown). The results suggest that HID-1 is a peripheral membrane protein tightly associated with the membrane.

To further determine the peripheral Golgi localization of HID-1, we adopted a permeabilization assay using a high concentration of digitonin according to a previously described protocol (Lorenz et al., 2006; Dimitrov et al., 2009). Digitonin has cholesterol-binding ability that can effectively permeabilize the plasma membrane without perturbing the structure of the Golgi apparatus. In this assay, we utilized a single transmembrane trans-Golgi marker TGN38-EGFP (Humphrey et al., 1993) as an integral membrane protein control and simultaneously recorded fluorescence with hHID-1-mKO before and after adding a high concentration of digitonin (60 $\mu \mathrm{M})$. As shown in Fig. 6, the fluorescence of hHID-1-mKO disappeared over time after adding digitonin; however the fluorescence of TGN38-EGFP only decreased slightly probably due to photobleaching. Together with the biochemical assay, the results strongly demonstrate that HID-1 is a peripheral membrane protein tightly associated with the Golgi apparatus but not a transmembrane protein predicted by the bioinformatic programs.

\section{HID-1 shuttles dynamically between the Golgi apparatus and the cytosol}

Being a peripheral membrane protein, HID-1 should shuttle between the Golgi apparatus and the cytosol. We analyzed the dynamic rate of hHID-EGFP in INS-1 cells by fluorescence recovery after photobleaching (FRAP) approach. A reported Golgi anchoring protein, Dymeclin, was used as a control, which is known to be a fast shuttling protein between the Golgi apparatus and the cytosol (Dimitrov et al., 2009). When EGFP-tagged Dymeclin was co-transfected with hHID1-mKO in INS-1 cells, we observed perfect co-localization of the two proteins (Fig. 7A). This co-localization was even maintained after disrupting the Golgi apparatus with BFA. The recovery of Dym-EGFP (EGFP-tagged at the C-terminus of Dymeclin) and HID-1-EGFP were then recorded by consecutive imaging after the photobleaching. As shown in Fig. 7B, the representative FRAP images of hHID-1-EGFP demonstrated that cytosolic hHID-1 could shuttle to Golgi membrane. The mobile fraction of hHID-1-EGFP only 
A

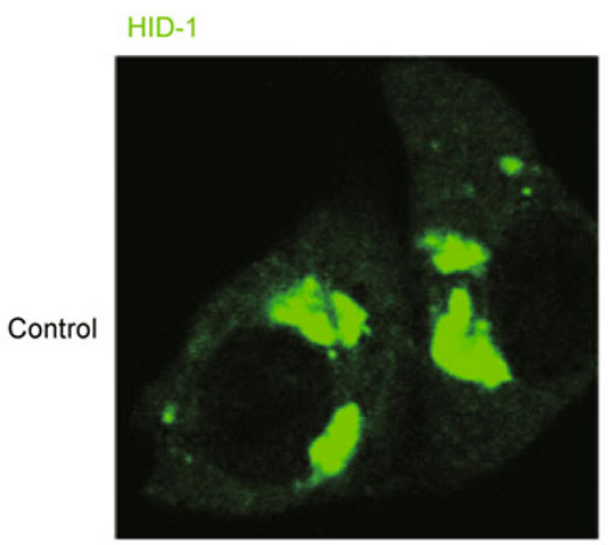

\section{Golgi}
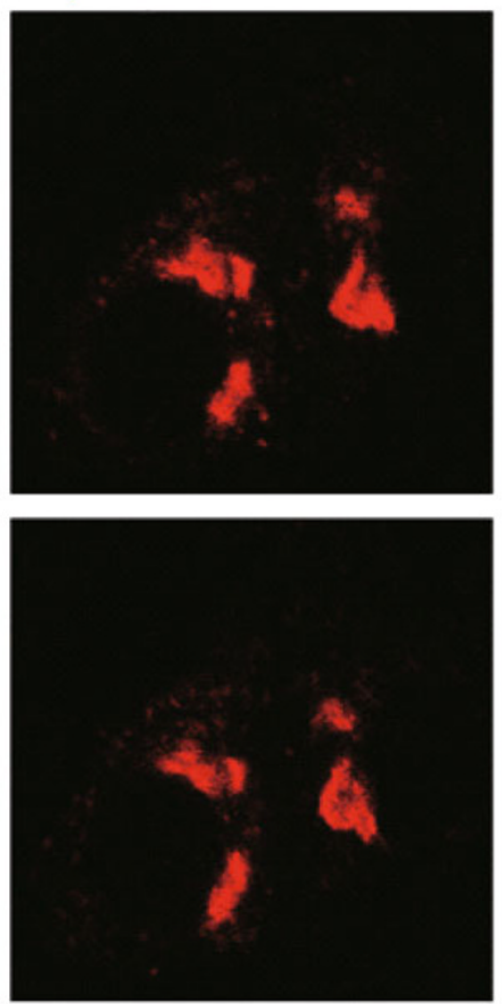

Merge
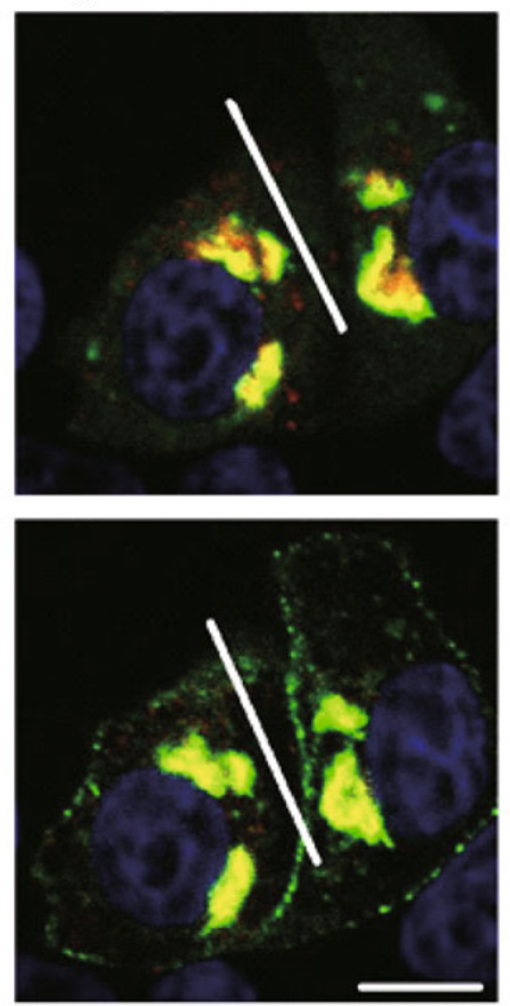

B
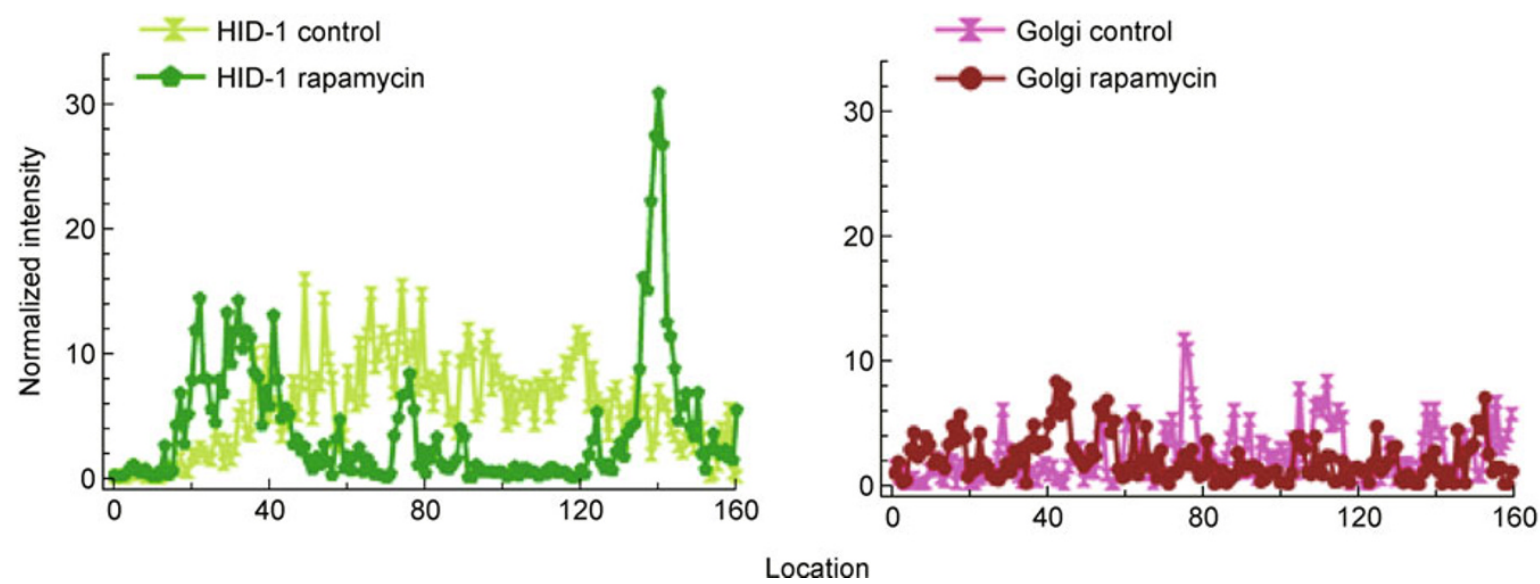

Figure 3. Demonstration of cytosolic portion of HID-1 by rapamycin-mediated heterodimerization of FKBP and FRB. (A) INS-1 cells were transfected with hHID-1-EGFP-FKBP, Golgi-TDimer2 and lyn11-FRB together. hHID-1-EGFP-FKBP and GolgiTDimer2 were observed to co-localize at the Golgi region (upper panel). After rapamycin treatment for 2 min, hHID-1-EGFP-FKBP was observed at the plasma membrane, whereas the localization of Golgi-TDimer2 was not affected. Scale bar $=10 \mu \mathrm{m}$. (B) The fluorescence intensity linescan profiles were generated along the white lines indicated in (A), suggesting the redistribution of $h H I D-1-$ EGFP-FKBP from cytosol to the plasma membrane after rapamycin treatment.

restored a small portion of the pre-bleaching fluorescent level in the Golgi region, consistent with the idea that HID-1 preferentially localizes to the Golgi apparatus. The half-time recovery of hHID-1-EGFP was calculated to be $16.4 \pm 0.1 \mathrm{~s}$ ( $n$
=23), while Dym-EGFP had a faster dynamics with a halftime of $5.3 \pm 0.1 \mathrm{~s}(n=17)$ (Fig. 7D). These results suggest that HID-1 dynamically shuttles between the Golgi apparatus and the cytosol. 


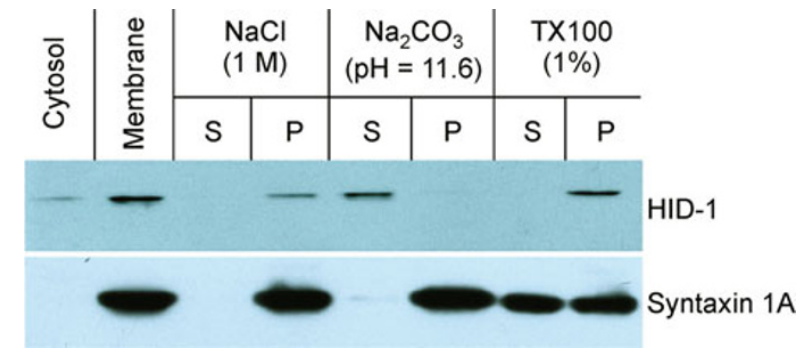

Figure 4. HID-1 is a peripheral membrane protein. After separation from the cytosol, INS-1 membrane fractions were treated with $1 \mathrm{M} \mathrm{NaCl}, 100 \mathrm{mM} \mathrm{Na}_{2} \mathrm{CO}_{3}(\mathrm{pH} 11.5)$, or $1 \%$ Triton $\mathrm{X}-100$ for $30 \mathrm{~min}$ at $4^{\circ} \mathrm{C}$ respectively, followed by ultra-speed centrifugation. The supernatants $(S)$ and pellets $(P)$ in different samples were detected by immunoblot with the hHID-1 antiserum and an anti-Syntaxin $1 \mathrm{~A}$ antibody.

\section{N-myristoylation of HID-1 plays a key role in its Golgi-localization}

Although no conserved domains or signal peptides could be predicted from the HID-1 primary sequence, a putative $\mathrm{N}$ terminal myristoylation site "MGSTDSKLN" was predicted by the "Myristoylator" software (prediction of $\mathrm{N}$-terminal myristoylation by neural networks, NMT). Protein N-myristoylation corresponds to the covalent attachment of a myristate, a 14carbon saturated fatty acid, to the $\mathrm{N}$-terminal glycine of eukaryotic proteins and promotes a weak and reversible membrane association in many cases. $\mathrm{N}$-myristoylation plays key roles in critical components of various cellular processes, such as signal transduction, apoptosis, and oncogenesis (de Jonge et al., 2000; Wright et al., 2009). To test the function of the predicted myristoylation site in HID-1, we mutated the amino acid "G" at position + 2 of hHID-1-mKO to a nonfunctional amino acid "A" (hHID-1(G2A)-mKO) and examined its co-localization with hHID-1-EGFP in living cells by confocal imaging. As shown in Fig. 8, in INS-1 cells hHID-1(G2A)-mKO detached from the Golgi apparatus and appeared to have a diffused cytosolic distribution, in contrast to the Golgilocalization of hHID-1-EGFP in the same cell. The results indicate that the predicted $\mathrm{N}$-myristoylation site is required for HID-1 binding to the Golgi apparatus.

\section{DISCUSSION}

The function of a given protein depends on the local environment where the protein resides. In this respect, it is crucial to determine the precise subcellular localization of a protein before concluding on its function. Various programs have predicted HID-1 protein as a transmembrane protein. In contrast to these predictions, we have verified that HID-1 is a peripheral membrane protein that associates primarily with the medial- and trans-Golgi membranes. Peripheral membrane proteins are associated with the surface of the membrane by their conformational structure (such as amphipathic helices, hydrophobic loops) and/or electrostatic interactions (involved with lipid-protein and/or protein-protein interactions) which can be disrupted by high concentration of salt solution, high $\mathrm{pH}$ buffers or metal chelating agents. Indeed, we found high $\mathrm{pH}(\mathrm{pH}$ 11.5) buffer released HID-1 from the membrane fraction to soluble fraction (Fig. 5). In addition, we demonstrated that HID-1 dissociated from the Golgi membrane upon permeabilization of plasma membrane by digitonin, in contrast to an integral transmembrane Golgi marker, TGN38 (Fig.6). These results demonstrate a membrane anchoring nature of HID-1 and suggest a cytosolic portion of HID-1 protein.

To further validate the cytosolic existence of HID-1, we established an original method based on rapamycinmediated heterodimerization of FKBP and FRB. In recent years, the advantages of the FKBP/FRB/rapamycin system (Standaert et al., 1990; Brown et al., 1994; Choi et al., 1996) have been shown by various kinds of significant applications including the localization and activity of Golgi-resident enzymes such as glycosyltransferase (Dube et al., 2006), and the rapid inactivation of endogenous proteins by specific siRNA-resistant sequence tagged FKBP (or FRB) (Robinson et al., 2010). Here, we have expanded the application of FKBP/FRB/rapamycin complex, providing a reliable shortcut to judge whether a certain protein has a cytosolic fraction. This method is robust as we observed rapid translocation of FKBP-tagged hHID-1 to the plasma membrane with concomitant reduction in cytosolic portion (Fig. 4). The existence of two pools of HID-1 proteins prompts us to speculate whether HID-1 can dynamically shuttle between the cytosol and the Golgi membrane, with a preference to the membrane. This speculation is in agreement with our FRAP experiments (Fig. 7) where we showed that cytosolic HID-1 could associate with Golgi membrane with a half-time of $\sim 16 \mathrm{~s}$. The association with Golgi membrane seems to be mediated primarily by $\mathrm{N}$-myristolylation of a glycine residue at the $\mathrm{N}$ terminal end. The functions of a large number of Golgi proteins with $\mathrm{N}$-myristoylation have already been established. For example, Arfs and GRASPs (Mironov and Pavelka, 2008) (such as GRASP55 and GRASP65) proteins are all targeted to the membrane by N-myristoylation (Lodge et al., 1997). Therefore, HID-1 may use a similar mechanism as these proteins for anchoring the corresponding membranes.

A striking discovery of this study is that HID-1 is a novel Golgi-localized protein with a preference to the medial- and trans-Golgi apparatus. The subcellular localization of HID-1 resembles its only paralog, Dymeclin (Dimitrov et al., 2009). Dymeclin is a protein recently identified as the translation product of the FLJ20071/FLJ90130/Dym gene (DYM), mutations of which are responsible for a severe autosomal-recessive skeletal dysplasia associated with mental delay, Dyggve-Melchior-Clausen syndrome (DMC, MIM\#223800) and a clinical variant without mental 
A Untreated

$0 \mathrm{~s} \quad 30 \mathrm{~s}$
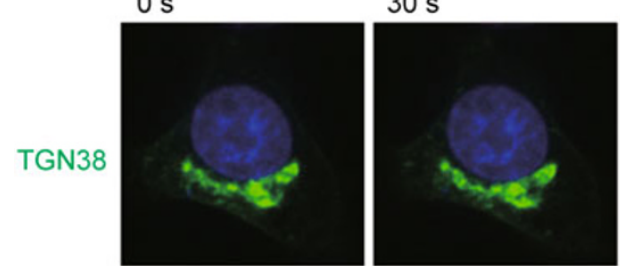

$100 \mathrm{~s}$

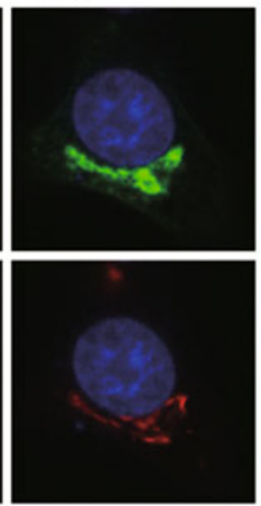

200

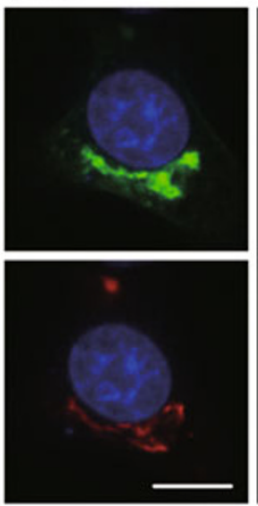

$200 \mathrm{~s}$

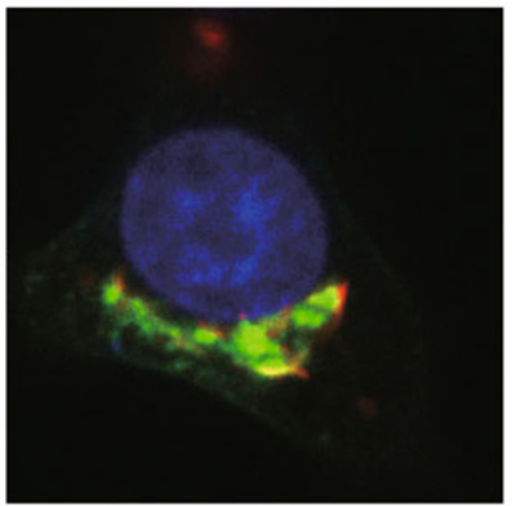

\section{Digitonin}

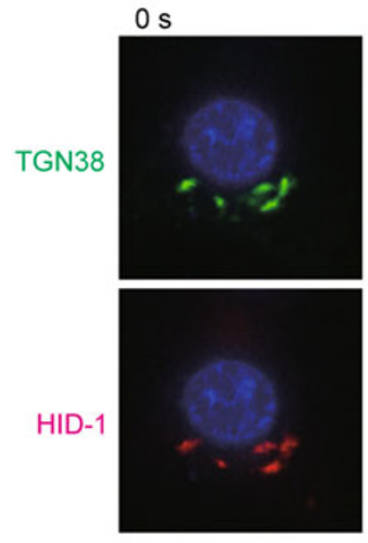

$30 \mathrm{~s}$
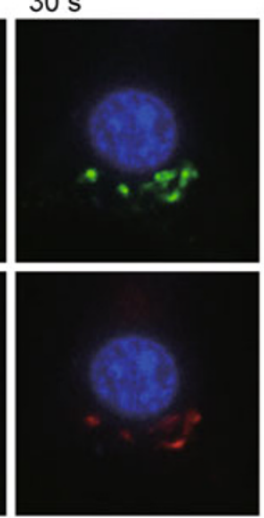

$100 \mathrm{~s}$

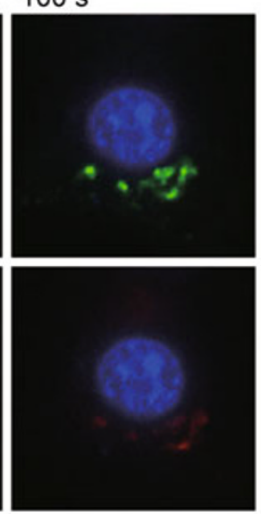

$200 \mathrm{~s}$

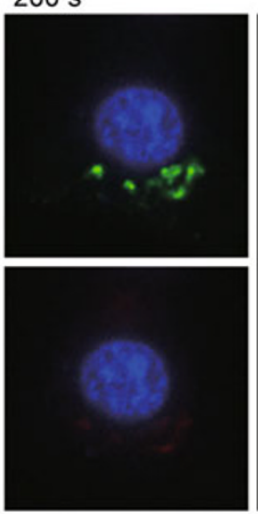

$200 \mathrm{~s}$

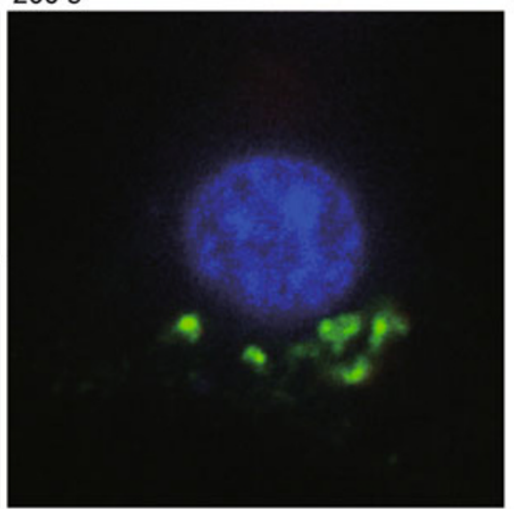

B

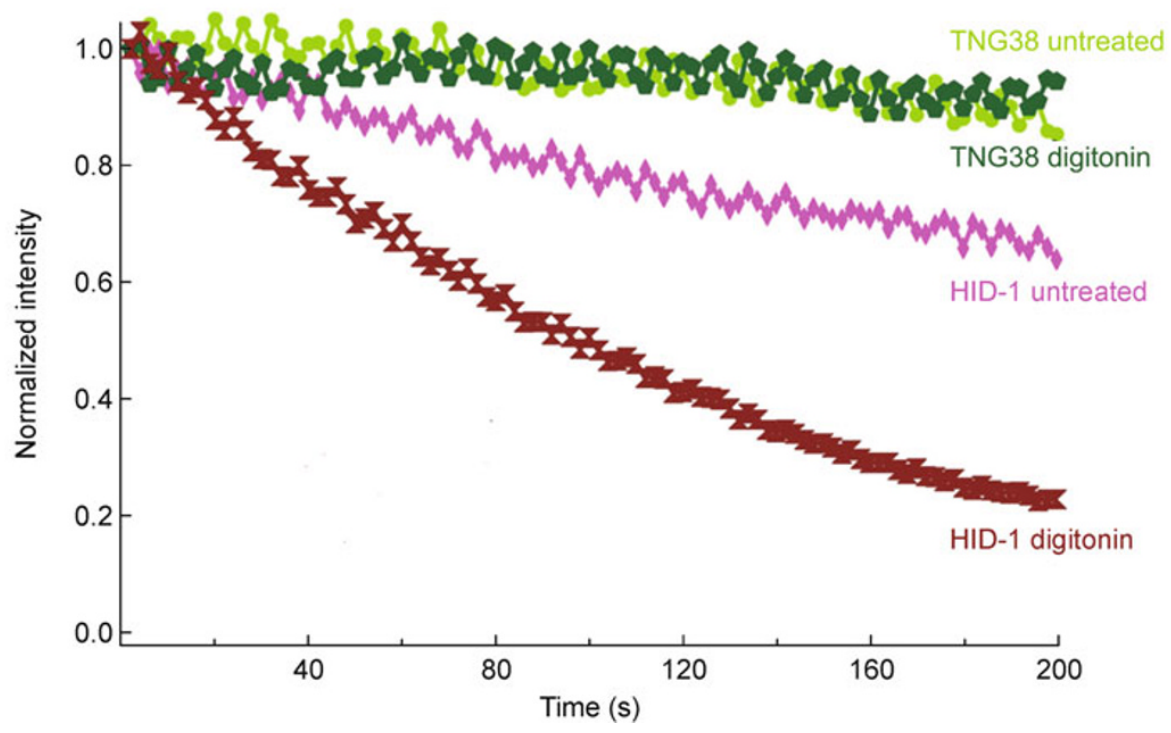

Figure 5. HID-1 dissociates from the Golgi membrane after the permeabilization of digitonin. (A) INS-1 cells were transfected with hHID-1-mKO (red) and TGN38-EGFP (green). Then imaging was performed on a spinning disk microscope before (control) and after digitonin treatment. Nuclei were labeled with Hoechst 33342 (blue). Scale bar $=10 \mu \mathrm{m}$. (B) Normalized fluorescent intensity plots of Golgi region at indicated time. 
A

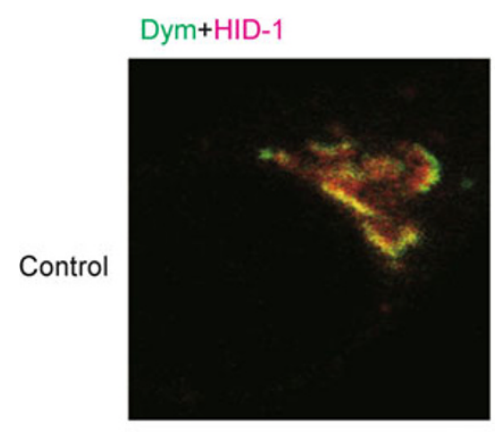

HID-1+GM
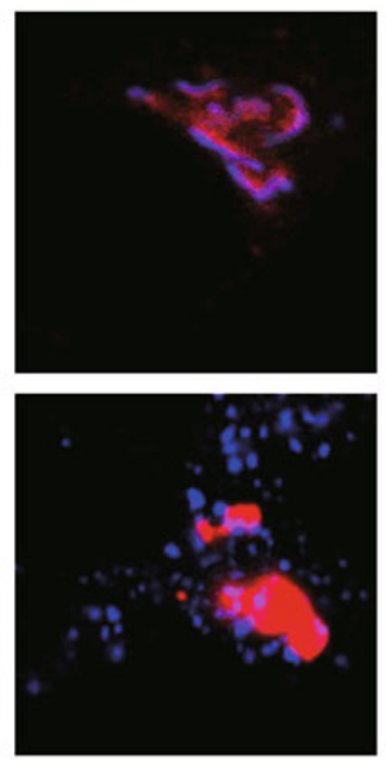

B

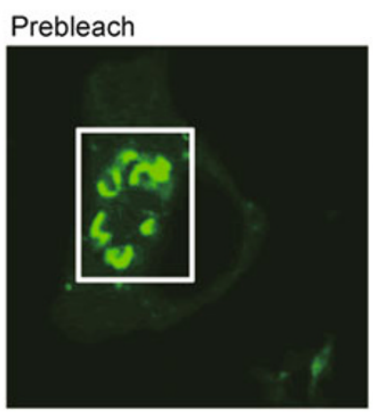

$0 \mathrm{~s}$

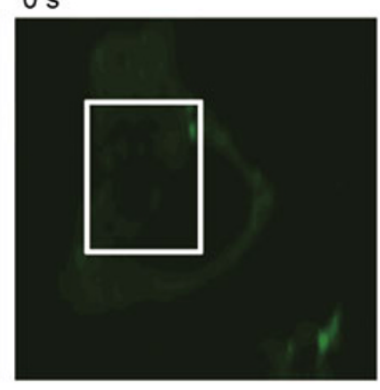

$50 \mathrm{~s}$
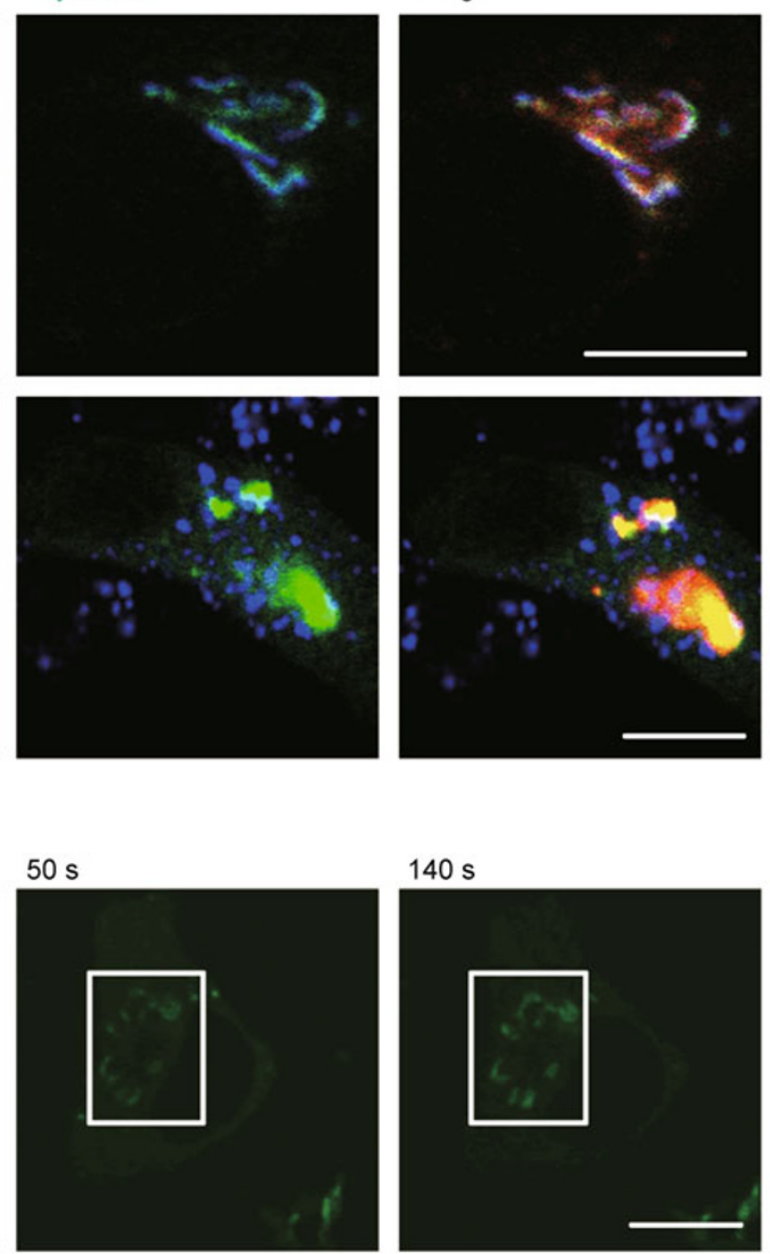

\begin{abstract}
Merge
\end{abstract}
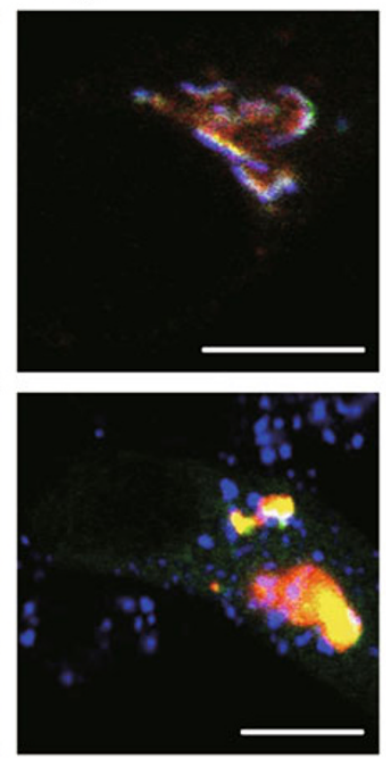

D

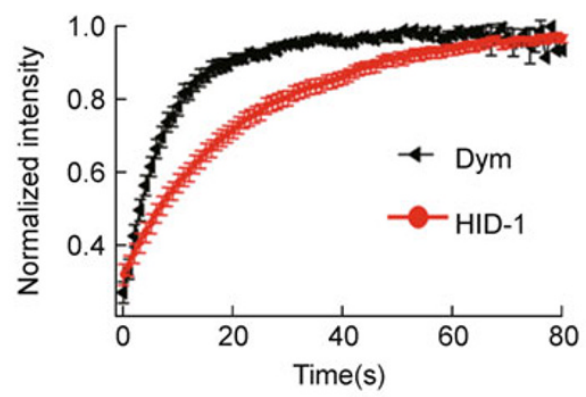

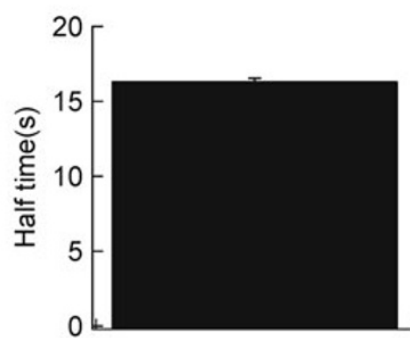

HID-1 $(n=23)$

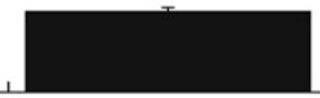

$\operatorname{Dym}(n=17)$

Figure 6. Dynamics of hHID-1 and Dymeclin on Golgi apparatus in INS-1 cells by FRAP approach. (A) Localization of hHID-1 and Dymeclin in INS-1 cells. Dym (Dym-EGFP, transfected); HID-1(hHID-1-mKO, transfected). GM: GM130 (cis-Golgi marker, endogenous, Cy5 used as the secondary antibody). Scale bar $=10 \mu \mathrm{m}$. (B) hHID-1-EGFP transiently expressed in INS-1 cells was imaged before and after photobleaching the Golgi region (framed by the rectangle) at different time points by Olympics FV1000 confocal microcopy. (C) Normalized fluorescent intensity recovery curve after photobleaching of Dym-EGFP and hHID-1-EGFP. (D) Quantified half recovery time of hHID-1-EGFP $(16.4 \pm 0.1 \mathrm{~s}, n=23)$ and Dym-EGFP $(5.3 \pm 0.1 \mathrm{~s}, n=17)$. 

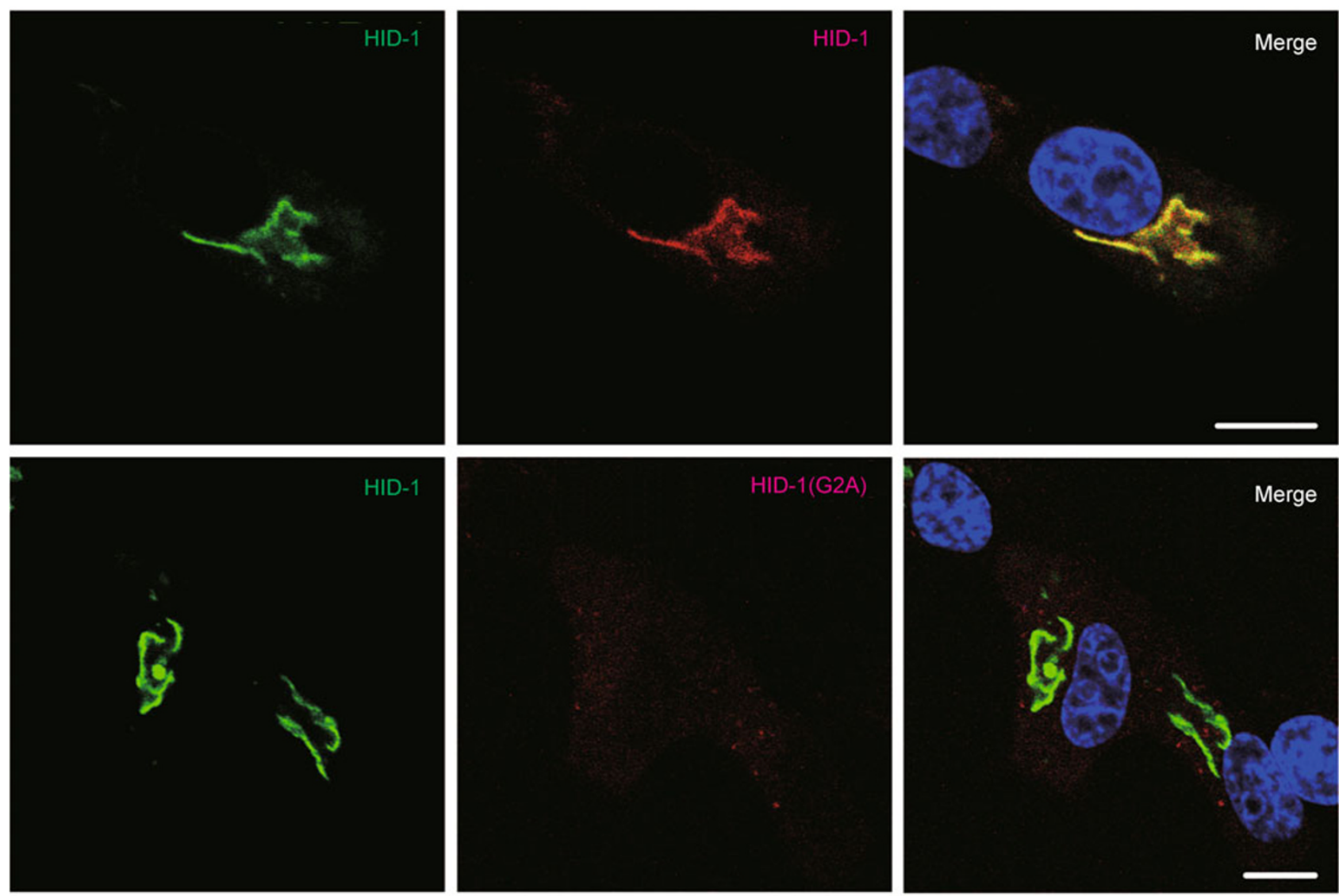

Figure 7. HID-1 anchors to the Golgi membrane by N-myristoylation. The upper panel shows that the localization of cotranfected hHID-1-EGFP (green) and hHID-1-mKO (red) in INS-1 cells, and the lower panel shows that co-transfected hHID-1-EGFP (green) and hHID-1(G2A)-mKO (red) in the same batch of INS-1 cells. Nuclei were labeled with Hoechst 33342 (blue). Scale bar= $10 \mu \mathrm{m}$.

amino acid protein which does not belong to any identified protein family. Except for a high homology with HID-1 protein, search for predictive structural and/or functional motives failed to provide any clue as to the function of Dymeclin (Cohn et al., 2003; El Ghouzzi et al., 2003). Electron microscopy revealed that Dymeclin associated with the Golgi apparatus and transitional vesicles of the reticulum-Golgi interface. In this study, we have shown that HID-1 co-localized pretty well with Dymeclin at Golgi region (upper panel of Fig. 7A). Interestingly, this co-localization even persisted after disrupting the Golgi structure by BFA (lower panel of Fig. 7A). These results suggest that HID-1 and Dymeclin reside on the same subdomain of Golgi apparatus.

The Golgi apparatus serves as a crossroad of intracellular trafficking, including ER-Golgi transport, Golgi-to-plasma membrane traffic, and transport from TGN to endosomes and lysosomes. Recent decades witness an exponential increase of proteins identified as peripheral membrane proteins of the Golgi apparatus, such as SNAPs (soluble NSF attachment proteins) (Colombo et al., 1998) and p230 (Kjer-Nielsen et al., 1999). Many peripheral membrane proteins have been found to be involved in intracellular trafficking in secretory pathway, such as P115 (Waters et al., 1992) and ARFs (Anders and Jurgens, 2008). Based on the subcellular localization, it has been proposed that Dymeclin might be involved in vesicular trafficking to and within Golgi apparatus. Considering previous results in C. elegans suggesting a role for hid-1 gene in the insulin pathway that regulates dauer formation and the current results that HID-1 co-localized with Dymeclin in subdomain of Golgi apparatus, we propose that HID-1 may function in the trafficking of cargos that are important for the sorting/biogenesis/maturation of dense core vesicles (DCVs). Further experiments are definitely in need to unravel the precise function of this mysterious protein.

\section{MATERIALS AND METHODS}

\section{Cell culture and transfection}

INS-1 cells were cultured in RPMI-1640 (Gibco) with $11.1 \mathrm{mM} \mathrm{D-}$ glucose plus $10 \%$ fetal bovine serum (Gibco), $1 \mathrm{mM}$ sodium pyruvate 
(Sigma), and $50 \mathrm{mM} \beta$-mercaptoethanol (Sigma), and were maintained at $37^{\circ} \mathrm{C}$ and $5 \% \mathrm{CO}_{2}$ in a humidified incubator. Cells were transiently transfected with Lipofectamine TM 2000 (Invitrogen) according to the manufacturer's instructions. After transfection, cells were grown in RPMI-1640 medium for $36 \mathrm{~h}$ and then processed.

\section{Plasmids}

The full-length Homo sapiens HID-1 was isolated from human brain cDNA, and was then cloned into Nhe I / Hind III sites of pEGFP-N1. For the construction of hHID1-mKO, EGFP was replaced by mKO, without other changes. The hHID-1(G2A)-mKO mutant was produced through replacement of amino acid " $G$ " at position +2 of hHID1-mKO with amino acid "A". Full-length of hHID-1 was tagged with FKBP and EGFP sequentially in the hHID-1-FKBP-EGFP plasmid. The Homo sapiens Dymeclin purchased from ProteinTech Group was cloned in pEGFP-N1 at Nhel/Xhol sites. In addition, Lyn11-FRB was a kind gift from Tobias Meyer (Stanford University, Palo Alto, CA, USA), and TGN38-EGFP was generously provided by Peter A. Greer (Queen's Cancer Research Institute, Canada). Golgi-EGFP ("Golgi" means 81 amino acids of the precursor to the human beta 1, 4-galactosyltransferase) was purchased from Clontech Laboratories, and EGFP was replaced by TDimer2 for the construction of Golgi-TDimer2.

\section{Antibodies}

For immunofluorescence, primary antibodies were used as following: anti-hHID-1 antiserum was produced from the blood of mice immunized with purified full-length human HID-1 recombinant protein expressed by AbMax Biotechnology Company (China). Commercial antibodies included mouse anti-Syntaxin1A (Sigma, S0664), mouse anti-FLAG (Sigma, F1804), rabbit anti-Syntaxin6 (Proteintech Group, 10841-1-AP), and mouse anti-GM130 (BD Transduction Laboratories 610822). All the secondary antibodies used for immunofluorescence were from Jackson ImmunoResearch.

\section{Subcellular fractionation for membrane protein extraction}

Three $10 \mathrm{~mm}$ plates of INS-1 cells were washed twice with $10 \mathrm{~mL}$ icecold PBS and scraped in $5 \mathrm{~mL}$ ice-cold PBS with $1 \mathrm{mM} \mathrm{PI}$ (protease inhibitor cocktail). Cells were then homogenized in $5 \mathrm{~mL}$ Buffer $A$ (0.3 $\mathrm{M}$ sucrose, $1 \mathrm{mM}$ EDTA, $1 \mathrm{mM} \mathrm{MgSO}$, $10 \mathrm{mM}$ MES-KOH, pH $6.5)$ by the Dounce homogenizer on ice. The homogenate (whole cell) was centrifuged at $1000 \times g$ for $5 \mathrm{~min}$ to remove unbroken cells and nuclear debris. The supernatant from the original $1000 \times g$ spin was used to separate cytosol from total membranes by centrifugation at $200,000 \times g$ for $30 \mathrm{~min}$ at $4^{\circ} \mathrm{C}$ in a Beckman TLA 100.3 rotor. The resultant pellets were subjected to treatment with different solvents (including $0.1 \mathrm{M} \mathrm{Na}_{2} \mathrm{CO}_{3}$ at $\mathrm{pH} 11.5,1 \mathrm{M} \mathrm{NaCl}$, or $1 \%$ Triton $\mathrm{X}-100$ ) by end-over-end mixing $\left(30 \mathrm{~min}, 4^{\circ} \mathrm{C}\right)$, and then centrifuged at $100,000 \times$ $g$ and $4^{\circ} \mathrm{C}$ for $30 \mathrm{~min}$. The supernatant and pellet were analyzed by Western blotting.

\section{Immunofluorescence and confocal microscopy analysis}

Indirect immunofluorescence experiments were performed as previously described with minor modifications. INS-1 cells were cultured onto glass coverslips after transfection and at approximately $36 \mathrm{~h}$ post-transfection, and cells were fixed with $4 \%(w / v)$ paraformaldehyde in PBS for 20 min at room temperature. After three washes with PBS, cells were permeabilized with $0.1 \%$ Triton X-100 in PBS for $5 \mathrm{~min}$, blocked by $5 \%$ goat serum, followed by incubation with primary antibodies diluted in PBS for $1 \mathrm{~h}$. Subsequently, cells were washed three times with PBS and incubated with secondary antibodies diluted in PBS for $1 \mathrm{~h}$. After washing three times with PBS, the cells were mounted using anti-fading reagents for imaging.

All confocal microscopy images (except the FRAP assay) were obtained using the Olympus FV500 Laser Scanning Confocal Microscopy and spinning-disk confocal microscopy. Confocal settings used for image capture were held constant in comparison experiments. Images were quantified and analyzed using Image $J$ software (NIH, USA). In the FRAP experiment, hHID-1-EGFP and Dym-EGFP were imaged by Olympus FV1000 Laser Scanning Confocal Microscopy every $3 \mathrm{~s}$ at a lower intensity illumination after selective photobleaching with a higher intensity.

\section{Bioinformatics analysis}

Prediction of the hydrophobic amino acid and transmembrane regions was performed using the following software programs: TMpred (http://www.ch.embnet.org/software/TMPRED_form.html), TMHMM2.0 (http://www.cbs.dtu.dk/services/TMHMM/), HMMTOP2.0 (http://www.enzim.hu/hmmtop/), DAS (http://www.sbc.su.se/ miklos/ DAS/), Toppred2 (http://www.sbc.su.se/ erikw/toppred2/). Posttranslational modification predictions were performed with the following program: Myristoylator-Prediction of $\mathrm{N}$-terminal myristoylation by neural networks.

\section{ABBREVIATIONS}

BFA, brefeldin A; EGFP, enhanced green fluorescent protein; mKO, monomeric Kushibara Orange; TDimer2, tandem dimer mutant of Dsred; FRAP, fluorescent recovery after photobleaching; DCV, dense core vesicle; TGF- $\beta$, transforming growth factor-beta; TGN, transGolgi network

\section{ACKNOWLEDGEMENTS}

We thank Professor Tobias Meyer (Stanford University, Palo Alto, CA) for kindly providing Lyn11-FRB plasmid; Professor Peter A Greer (Queen's Cancer Research Institute, Canada) for generously providing TGN38-EGFP plasmid; and Drs. Liangyi Chen and Wei Feng for valuable discussions. This work was supported by grants from the National Science Foundation of China (Grant Nos. 30870564, and 30900268), The Beijing Natural Science Foundation (No. 5092017), the Major State Basic Research Program of China (No. 2010CB833701), and the CAS Project (KSCX2-SW-224 and Novo Nordisk-CAS to $\mathrm{P} \mathrm{Xu}$ ).

\section{REFERENCES}

Ailion, M., and Thomas, J.H. (2003). Isolation and characterization of high-temperature-induced Dauer formation mutants in Caenorhabditis elegans. Genetics 165, 127-144.

Anders, N., and Jürgens, G. (2008). Large ARF guanine nucleotide exchange factors in membrane trafficking. Cell Mol Life Sci 65, 3433-3445. 
Apfeld, J., and Kenyon, C. (1998). Cell nonautonomy of C. elegans daf-2 function in the regulation of diapause and life span. Cell 95, 199-210.

Birnby, D.A., Link, E.M., Vowels, J.J., Tian, H., Colacurcio, P.L., and Thomas, J.H. (2000). A transmembrane guanylyl cyclase (DAF-11) and Hsp90 (DAF-21) regulate a common set of chemosensory behaviors in caenorhabditis elegans. Genetics 155, 85-104.

Brown, E.J., Albers, M.W., Shin, T.B., Ichikawa, K., Keith, C.T., Lane, W.S., and Schreiber, S.L. (1994). A mammalian protein targeted by G1-arresting rapamycin-receptor complex. Nature 369, 756758.

Campellone, K.G., Webb, N.J., Znameroski, E.A., and Welch, M.D. (2008). WHAMM is an Arp2/3 complex activator that binds microtubules and functions in ER to Golgi transport. Cell 134, 148-161.

Cassada, R.C., and Russell, R.L. (1975). The dauerlarva, a postembryonic developmental variant of the nematode Caenorhabditis elegans. Dev Biol 46, 326-342.

Choi, J., Chen, J., Schreiber, S.L., and Clardy, J. (1996). Structure of the FKBP12-rapamycin complex interacting with the binding domain of human FRAP. Science 273, 239-242.

Cohn, D.H., Ehtesham, N., Krakow, D., Unger, S., Shanske, A., Reinker, K., Powell, B.R., and Rimoin, D.L. (2003). Mental retardation and abnormal skeletal development (Dyggve-Melchior-Clausen dysplasia) due to mutations in a novel, evolutionarily conserved gene. Am J Hum Genet 72, 419-428.

Colombo, M.I., Gelberman, S.C., Whiteheart, S.W., and Stahl, P.D. (1998). N-ethylmaleimide-sensitive factor-dependent alpha-SNAP release, an early event in the docking/fusion process, is not regulated by Rab GTPases. J Biol Chem 273, 1334-1338.

de Jonge, H.R., Hogema, B., and Tilly, B.C. (2000). Protein Nmyristoylation: critical role in apoptosis and salt tolerance. Sci STKE 2000, pe1.

Dimitrov, A., Paupe, V., Gueudry, C., Sibarita, J.B., Raposo, G., Vielemeyer, O., Gilbert, T., Csaba, Z., Attie-Bitach, T., CormierDaire, V., et al. (2009). The gene responsible for Dyggve-MelchiorClausen syndrome encodes a novel peripheral membrane protein dynamically associated with the Golgi apparatus. Hum Mol Genet $18,440-453$.

Dube, D.H., de Graffenried, C.L., and Kohler, J.J. (2006). Regulating cell surface glycosylation with a small-molecule switch. Methods Enzymol 415, 213-229.

El Ghouzzi, V., Dagoneau, N., Kinning, E., Thauvin-Robinet, C., Chemaitilly, W., Prost-Squarcioni, C., Al-Gazali, L.I., Verloes, A., Le Merrer, M., Munnich, A., et al. (2003). Mutations in a novel gene Dymeclin (FLJ20071) are responsible for Dyggve-Melchior-Clausen syndrome. Hum Mol Genet 12, 357-364.

Fielenbach, N., and Antebi, A. (2008). C. elegans dauer formation and the molecular basis of plasticity. Genes Dev 22, 2149-2165.

Gleeson, P.A., Teasdale, R.D., and Burke, J. (1994). Targeting of proteins to the Golgi apparatus. Glycoconj J 11, 381-394.

Humphrey, J.S., Peters, P.J., Yuan, L.C., and Bonifacino, J.S. (1993). Localization of TGN38 to the trans-Golgi network: involvement of a cytoplasmic tyrosine-containing sequence. J Cell Biol 120, 1123-1135.

Inoue, T., and Thomas, J.H. (2000a). Suppressors of transforming growth factor-beta pathway mutants in the Caenorhabditis elegans dauer formation pathway. Genetics 156, 1035-1046.
Inoue, T., and Thomas, J.H. (2000b). Targets of TGF-beta signaling in Caenorhabditis elegans dauer formation. Dev Biol 217, 192-204.

Killisch, I., Steinlein, P., Römisch, K., Hollinshead, R., Beug, H., and Griffiths, G. (1992). Characterization of early and late endocytic compartments of the transferrin cycle. Transferrin receptor antibody blocks erythroid differentiation by trapping the receptor in the early endosome. J Cell Sci 103, 211-232.

Kjer-Nielsen, L., van Vliet, C., Erlich, R., Toh, B.H., and Gleeson, P.A. (1999). The Golgi-targeting sequence of the peripheral membrane protein p230. J Cell Sci 112, 1645-1654.

Koh, S., Yamamoto, A., Inoue, A., Inoue, Y., Akagawa, K., Kawamura, Y., Kawamoto, K., and Tashiro, Y. (1993). Immunoelectron microscopic localization of the HPC-1 antigen in rat cerebellum. J Neurocytol 22, 995-1005.

Lewis, J.L., Dong, M., Earles, C.A., and Chapman, E.R. (2001). The transmembrane domain of syntaxin $1 \mathrm{~A}$ is critical for cytoplasmic domain protein-protein interactions. J Biol Chem 276, 15458-15465.

Liang, Z., and Li, G. (2000). Mouse prenylated Rab acceptor is a novel Golgi membrane protein. Biochem Biophys Res Commun 275, 509-516.

Lippincott-Schwartz, J., Yuan, L., Tipper, C., Amherdt, M., Orci, L., and Klausner, R.D. (1991). Brefeldin A's effects on endosomes, lysosomes, and the TGN suggest a general mechanism for regulating organelle structure and membrane traffic. Cell 67, 601-616.

Lodge, J.K., Jackson-Machelski, E., Devadas, B., Zupec, M.E., Getman, D.P., Kishore, N., Freeman, S.K., McWherter, C.A., Sikorski, J.A., and Gordon, J.I. (1997). N-myristoylation of Arf proteins in Candida albicans: an in vivo assay for evaluating antifungal inhibitors of myristoyl-CoA: protein N-myristoyltransferase. Microbiology 143, 357-366.

Lorenz, H., Hailey, D.W., Wunder, C., and Lippincott-Schwartz, J. (2006). The fluorescence protease protection (FPP) assay to determine protein localization and membrane topology. Nat Protoc 1, 276-279.

Luo, X., Feng, L., Jiang, X., Xiao, F., Wang, Z., Feng, G.S., and Chen, Y. (2008). Characterization of the topology and functional domains of RKTG. Biochem J 414, 399-406.

Luzio, J.P., Brake, B., Banting, G., Howell, K.E., Braghetta, P., and Stanley, K.K. (1990). Identification, sequencing and expression of an integral membrane protein of the trans-Golgi network (TGN38). Biochem J 270, 97-102.

Mironov, A., and Pavelka, M. (2008). The Golgi Apparatus: State of the Art 110 Years After Camillo Golgi's Discovery. New York: Springer-Verlag Gmbh, Wien.

Nakamura, N., Rabouille, C., Watson, R., Nilsson, T., Hui, N., Slusarewicz, P., Kreis, T.E., and Warren, G. (1995). Characterization of a cis-Golgi matrix protein, GM130. J Cell Biol 131, 1715-1726.

Ponnambalam, S., Girotti, M., Yaspo, M.L., Owen, C.E., Perry, A.C., Suganuma, T., Nilsson, T., Fried, M., Banting, G., and Warren, G. (1996). Primate homologues of rat TGN38: primary structure, expression and functional implications. J Cell Sci 109, 675-685.

Riddle, D. (1997). C. elegans II. New York: CSHL Press.

Robinson, M.S., Sahlender, D.A., and Foster, S.D. (2010). Rapid inactivation of proteins by rapamycin-induced rerouting to mitochondria. Dev Cell 18, 324-331. 
Standaert, R.F., Galat, A., Verdine, G.L., and Schreiber, S.L. (1990). Molecular cloning and overexpression of the human FK506binding protein FKBP. Nature 346, 671-674.

Suh, B.C., Inoue, T., Meyer, T., and Hille, B. (2006). Rapid chemically induced changes of Ptdlns(4,5)P2 gate $\mathrm{KCNQ}$ ion channels. Science 314, 1454-1457.

Trus, M., Wiser, O., Goodnough, M.C., and Atlas, D. (2001). The transmembrane domain of syntaxin $1 \mathrm{~A}$ negatively regulates voltage-sensitive $\mathrm{Ca}(2+)$ channels. Neuroscience 104, 599-607.

Waters, M.G., Clary, D.O., and Rothman, J.E. (1992). A novel 115-kD peripheral membrane protein is required for intercisternal transport in the Golgi stack. J Cell Biol 118, 1015-1026.
Wright, M.H., Heal, W.P., Mann, D.J., and Tate, E.W. (2009). Protein myristoylation in health and disease. J Chem Biol 3, 19-35.

Yamaguchi, N., and Fukuda, M.N. (1995). Golgi retention mechanism of beta-1,4-galactosyltransferase. Membrane-spanning domaindependent homodimerization and association with alpha- and beta-tubulins. J Biol Chem 270, 12170-12176.

Yu, Y., Wang, L.F., Jiu, Y.M., Zhan, Y., Liu, L., Xia, Z.P., Song, E.L., Xu, P.Y., Xu, T. (2011). HID-1 is a novel player in the regulation of neuropeptide sorting. Biochem J. Doi: 10.1042/BJ20110027.

Zerial, M., Melancon, P., Schneider, C., and Garoff, H. (1986). The transmembrane segment of the human transferrin receptor functions as a signal peptide. EMBO J 5, 1543-1550. 